\title{
ENSAIO SOBRE A VOZ
}

\author{
Daiane Neumann* \\ Universidade Federal de Pelotas \\ Centro de Letras e Comunicação \\ Pelotas, RS, Brasil
}

\begin{abstract}
Resumo: O presente artigo trata de uma temática pouco considerada e discutida nos estudos da linguagem, qual seja, a voz. Para fazê-lo, lança mão de reflexões propostas acerca da construção do objeto voz em diferentes perspectivas teóricas e em diferentes campos do conhecimento. O objetivo de fazer a passagem por diferentes concepções de voz é buscar elucidar a concepção de linguagem que subjaz a cada uma delas. Por fim, através da alteração do ponto de vista acerca da linguagem, é apresentada a proposta de uma antropologia histórica da voz, ancorada no projeto de uma antropologia histórica da linguagem, apresentado em Meschonnic (1982/2009).
\end{abstract}

Palavras-chave: Voz. Linguagem. Antropologia histórica da voz.

\section{INTRODUÇÃO}

No presente artigo, dedico-me a refletir acerca de uma temática que foi pouco discutida e, consequentemente, negligenciada nos debates que se circunscrevem aos estudos da linguagem, qual seja, a voz.

Essa temática esteve presente em diferentes campos de estudos, conforme será percebido ao longo do texto, na filosofia, nos estudos da linguagem, nos estudos literários. No entanto, mesmo quando se elege a voz como objeto de investigação dentro dos estudos da linguagem, as discussões e reflexões não se circunscrevem apenas a esse domínio, mas fazem interfaces com outros campos de estudo, como é o caso de Fónagy (1983), que observa a voz sob a perspectiva cotidiana, artística, psicopatológica e ontogenética, e de Parret (2002), que o faz sob a perspectiva da semiótica, da psicologia da percepção, da retórica, da musicologia.

Decorre desse tratamento interdiciplinar do elemento da voz a necessidade de partir das discussões de outros domínios do conhecimento, e mesmo das discussões através de itnerfaces, nos estudos da linguagem, para que se possa propor uma nova abordagem, um novo conceito de voz, a partir da perspectiva a que este trabalho se filia.

De acordo com Meschonnic (1989/2006, p. 56-57), "l'idée que vous avez du langage est votre portrait", ou seja, a visão de linguagem que sustentamos é o nosso retrato, não somente porque mostra o que pensamos sobre língua/linguagem, mas também a nossa concepção de sujeito, de subjetividade, da relação entre subjetividades, da relação

\footnotetext{
* Professora do curso de Letras e do Programa de Pós-Graduação em Letras da Universidade Federal de Pelotas. E-mail:daiane_neumann@hotmail.com
} 
do homem com a língua, com ele mesmo, com o outro, com o mundo, com a cultura, com a sociedade.

Partindo dessa premissa, discutirei, neste artigo, acerca de diferentes abordagens para o tema da voz, buscando observar a concepção de linguagem que subjaz a cada uma delas, para, ao final, levantar considerações basilares e de cunho teórico que estariam envolvidas na elaboração de uma noção de voz que considere a linguagem a partir do ponto de vista de uma antropologia histórica ${ }^{1}$.

\section{A VOZ FENOMENOLÓGICA}

Jacques Derrida, em La voix et le phénomène, publicado pela primeira vez em 1967, propõe-se a discutir sobre a voz. Dessa forma, o filósofo, ao retomar a reflexão apresentada pela fenomenologia de Husserl, introduz a voz como o lugar do "privilégio da presença como consciência" (DERRIDA, 1994, p. 23). A fala viva, a espiritualidade do sopro como phoné seria o elemento da significação ou a substância da expressão que preservaria melhor ao mesmo tempo a identidade e a presença viva sob todas suas formas.

Existiria, segundo Derrida (1994), um esforço tenaz, oblíquo e laborioso da fenomenologia para conservar a fala, para afirmar a ligação de essência entre o logos e a phoné. No entanto, no privilégio da consciência estaria a possibilidade da viva voz. Ou seja, seria na voz fenomenológica que o filósofo reconheceria uma afinidade de origem com o logos em geral, e não na substância sonora ou na voz física.

A voz fenomenológica é, então, concebida como a voz em sua "carne transcendental" (1994, p. 23), como o sopro, a animação intencional que transforma o corpo da palavra em carne. A voz fenomenológica seria, assim, "esta carne espiritual que continua a falar e a estar presente a si - a ouvir-se - na ausência do mundo" (1994, p. 23).

Mesmo tendo Husserl pretendido manter uma origem silenciosa, "pré-expresssiva", do vivido, Derrida mostra que a consciência de si só apareceria na sua relação com um objeto cuja presença poderia ser mantida e repetida, e que essa consciência de si não seria jamais perfeitamente estrangeira ou anterior à possibilidade da linguagem. Em Derrida, é cada vez mais difícil discernir o elemento da consciência do elemento da linguagem.

Para Derrida (1994), a voz não exigiria a intervenção de nenhuma superfície determinada no mundo, se produziria no mundo como autoafecção pura, seria uma substância significante absolutamente disponível. Essa autoafecção pura seria, para o filósofo, a possibilidade da "subjetividade" ou do "para-si". A voz suporia, na profundidade da unidade o som e a phoné - o primeiro está no mundo, a segunda é concebida no sentido fenomenológico. Essa unidade de som e de voz é que permitiria a esta última se produzir no mundo como autoafecção pura. Esta instância escaparia à distinção entre a intramundanidade e a transcendentalidade e, ao mesmo tempo, tornaria tal autoafecção possível.

\footnotetext{
1 A problemática de uma antropologia histórica da linguagem encontra-se discutida na obra do poeta, linguista e tradutor Henri Meschonnic. Essa problemática, conforme pontua Trabant (2005), constitui-se a partir do pensamento de Wilhelm von Humboldt, Ferdinand de Saussure e Émile Benveniste.
} 
Disso decorre que falar a alguém seria se ouvir falar, ouvir a si mesmo; ao mesmo tempo que, se somos ouvidos pelo outro, este repete imediatamente em si o ouvir-falar na forma mesma como eu o produzi. Ele reproduz a autoafecção pura sem o recurso a uma exterioridade. Essa possibilidade de reprodução ocorre como o fenômeno de uma matriz ou de um poder sem limite sobre o significante, que tem a forma da não exterioridade. Segundo Derrida (1994), na essência teleológica da fala, idealmente, seria possível que o significante fosse absolutamente próximo do significado visado pela intuição e guiasse o querer-dizer. Esse significante se tornaria diáfano em razão da proximidade absoluta do significado.

Essa autoafecção como operação da voz suporia uma diferença pura que dividiria a presença em si e na qual se enraizaria a possibilidade de tudo o que se crê poder excluir da autoafecção: o espaço, o fora, o mundo, o corpo, etc. Nenhuma redução transcendental pura seria possível, ao se admitir que a autoafecção seria a condição da presença em si. No entanto, seria necessário passar por ela, a fim de alcançar a diferença o mais próximo dela mesma. Não se trataria de alcançar sua identidade, sua pureza, sua origem, mas sim o movimento da diferença.

A crítica derridiana à categoria da presença, segundo Cavarero (2011), tem um espectro muito vasto, no qual se inserem a presença do objeto, a presença do sentido à consciência, a presença a si na palavra dita viva e na autoconsciência. Dessa forma, para a filósofa, tal crítica compreende tanto os sistemas de inspiração platônica centrados no objeto (o ser, a ideia, a forma original), como as filosofias modernas centradas no sujeito (consciência, autoconsciência). Contudo, devido a seu interesse por Husserl, Derrida privilegiaria o âmbito inteiramente moderno do sujeito, no qual a evidência do fundamento corresponde a uma forma imediata da presença a si que vê como protagonista a consciência pura.

Derrida estaria trabalhando, assim, com um conceito solipsístico de subjetividade de consciência. Tratar-se-ia, segundo a filósofa, tal como em Descartes, de uma subjetividade toda redobrada sobre si mesma, fechada e autorreferencial, que não tem necessidade de nenhum mundo exterior para fundar o regime de verdade. Portanto, o exercício da palavra acaba por ser entendido como um ouvir-se falar ou como um solilóquio, quase como se os seres humanos abrissem a boca para falar a si mesmos ou, quando falassem a outros, prestassem atenção no que dizem eles mesmos, e não no que dizem os outros. O diálogo se tornaria praticamente uma duplicação de monólogos.

Da mesma maneira, em Derrida, a constituição de uma subjetividade não depende de uma intersubjetividade. Ou seja, o "eu" não necessita de um "tu" para existir, não necessita de um interlocutor, de uma sociedade. Embora Derrida reconheça que a consciência de si e, consequentemente, a constituição de objetos ideais não seriam jamais perfeitamente estrangeiros ou anteriores à possibilidade de linguagem, o filósofo não reconhece que a constituição dos sujeitos e, consequentemente, da subjetividade, bem como da intersubjetividade, se dê na e pela linguagem. Não há, dessa forma, uma distinção entre o homem e o sujeito da linguagem. Tais posições levam à constatação de que sujeito e sociedade são concebidos em relação de oposição. 
Ainda no domínio da filosofia, Adriana Cavarero discute sobre a voz a partir da concepção desta como ontologia vocálica da unicidade. Essa discussão será objeto da próxima seção.

\section{A VOZ COMO ONTOLOGIA VOCÁLICA DA UNICIDADE}

Em 2003, Adriana Cavarero publica A più voci: filosofia dell'espressione vocale, obra que foi traduzida no Brasil em 2011, e tem como título Vozes plurais: filosofia da expressão vocal. Em tal reflexão, a autora busca pensar a relação entre a voz e a palavra como uma relação de unicidade que, mesmo soando principalmente na voz que ainda não é palavra, continua a ressoar na palavra a que a voz humana é constitutivamente destinada.

Para Flavio Terrigno Barbeitas, que escreve a apresentação da tradução brasileira da obra, Cavarero enfrenta o tema da voz naquilo que ela possui de mais valioso, o fato de que cada voz é única, singular, capaz justamente de desvelar o ser também único em carne e osso que a emite. A filósofa estaria, assim, voltando-se contra a prática tradicional que, em proveito de abstrações, sempre relegou a um plano absolutamente secundário a existência encarnada, única, singular e irreproduzível daquilo que, nas palavras de Barbeitas, "cada um de nós efetivamente é" (2011, p. 9)

A prevenção ao sonoro fazia parte do próprio léxico utilizado por Platão para dar forma à noção de saber e de conhecimento teórico, na maioria das vezes derivado da visão e a ele sempre referido. Cavarero (2011) mostra que a desconfiança em relação à sonoridade se espalha por seus diálogos com o propósito claro de garantir a supremacia de um logos fundado na clareza do conceito contra os efeitos não só diversivos como perigosos de uma palavra misturada ao som. Essa seria, para a filósofa, a principal razão para a célebre expulsão do poeta da cidade, na República.

A liberdade de combinação de palavras, mesmo que comprovada, não seria para a autora um indício suficiente da unicidade de quem fala. No entanto, mesmo que as palavras pronunciadas fossem as mesmas, a voz seria sempre diversa de outras vozes. $\mathrm{O}$ prazer, portanto, de dar forma própria às ondas sonoras faria parte da autorrevelação vocálica.

A voz, mais do que revelar, comunicaria precisamente a unicidade verdadeira, vital e perceptível de quem a emite. Assim, uma voz única não sinalizaria nada além de si mesma. Ela comunicaria os dados da existência: a unicidade e a condição relacional, mas também a diferença sexual e a idade.

A postura teórica de Cavarero se contrapõe a uma filosofia tradicional que renega a singularidade, a unicidade, a irrepetibilidade para buscar abstrações generalizadoras que possam resultar em classificações e regularidades. Ademais, a filósofa ressalta que foi imperativo a Platão, a fim de garantir a supremacia do logos fundado na clareza do conceito, a desconfiança em relação à sonoridade. O elemento da voz, da sonoridade, transforma-se assim naquele que é responsável pelo elemento da singularidade da unicidade.

A filósofa faz uma crítica à linguística ao afirmar que a "voz - estudada na perspectiva da linguagem e, ainda mais, numa perspectiva que entende a linguagem como 
sistema - torna-se a esfera geral das articulações sonoras na qual a unicidade do som é, paradoxalmente, aquilo que não soa" (2011, p. 95). Dessa forma, a linguagem concebida como código aspiraria ao universal e, consequentemente, tornaria impeceptível na voz o próprio da voz, pois "a unicidade plural das vozes não passa pelo filtro metodológico do ouvido linguístico" (2011, p. 25).

No entanto, é exatamente no trabalho de um linguista, Émile Benveniste, que se pode buscar sustentação para pensar a singularidade da voz, na medida em que ele se opõe, ainda em meados do século XX, a um modelo de ciência que busca classificações, regularidades, e propõe que se pense a linguagem a partir da perspectiva do sentido, do singular, do único, do particular.

Apesar de a filósofa italiana citar Benveniste ao final do capítulo 6, intitulado $A \mathrm{voz}$ e a linguagem, ao dizer que "[...] a relação entre as ideias, a sua originária conexão 'harmônica' funda o princípio relacional que opera em qualquer nível de um logos entendido benvenistianamente - como estrutura em que cada elemento recebe a sua razão de ser do todo que ajude a compor" (2011, p. 82), parece estar limitada a uma leitura estruturalista da obra do linguista. Claramente, não reconhece em Benveniste a pontencialidade para discutir questões de linguagem, e não apenas de língua enquanto sistema, e para pensar o discurso em sua singularidade, unicidade, particularidade.

Em "Semiologia da língua", Benveniste apresenta uma distinção entre o que denominou mundo semântico e mundo semiótico. O domínio semiótico seria aquele que "designa o modo de significação que é próprio do SIGNO linguístico e que o constitui como unidade" (BENVENISTE, 2006a, p. 64), já no domínio semântico "entramos no modo específico da significância que é engendrado pelo DISCURSO" (BENVENISTE, 2006a, p. 65). Dessa forma, um pensamento da individuação, do singular, do particular só pode recusar o signo que "existe em si, funda a realidade da língua, mas [...] não encontra aplicações particulares", enquanto a frase, "expressão do semântico, não é senão particular" (BENVENISTE, 2006b, p. 230).

Na constatação feita por Cavarero de que os estudos linguísticos ligados ao domínio do semiótico não dão conta da unicidade plural da voz, é bastante importante que se observe que estudar a voz não significa necessariamente considerá-la apenas como som, mas sim, e principalmente, em seu caráter singular, único, particular, o que só pode ser feito, em uma perspectiva benvenistiana, ao pensá-la a partir do domínio semântico, ou seja, do discurso, onde há espaço para a constituição de subjetividades. Prova disso é que a linguística trata dos sons da língua, contudo, isso não significa que se dedique ao estudo da voz. Conforme lembra Parret (2002), a voz é o lugar da alteridade radical. À voz está, assim, muito mais arraigado o pensar a subjetividade, a unicidade, o particular, do que propriamente o som.

Meschonnic (1982/2009) considera que a voz é o elemento mais pessoal e mais íntimo, assim como o sujeito, é imediatamente atravessado por tudo o que faz uma época. Dessa forma, a voz e seu discurso, o discurso e a sua voz são juntos o significante e o significado do signo, são concebidos como necessários um ao outro.

Ao fazer uma investigação sobre a ontologia da voz, Cavarero (2011) afirma que o âmbito da voz seria constitutivamente mais amplo do que o da palavra, na medida em que o excederia, e que um dos vícios capitais do logocentrismo seria reduzir esse excedente à 
insensatez. Assim, a filósofa busca pensar a relação entre voz e palavra como uma relação de unicidade que, mesmo soando principalmente na voz que ainda não é palavra, continuaria a ressoar na palavra a que a voz humana é constitutivamente destinada. De acordo com tal proposta, o sentido transitaria da esfera acústica à palavra; nele, comunicar-se-ia, acima de tudo, para além de conteúdos específicos que as palavras comunicam, a racionalidade acústica, empírica e material das vozes singulares.

Em tal reflexão de Cavarero, podemos perceber que sua discussão perpassa a relação especificamente entre voz e língua, enquanto sistema de signos, e não entre voz e linguagem ${ }^{2}$, entre voz e discurso. A voz concebida em sua indissociabilidade com o discurso jamais poderia ser pensada fora da linguagem, pois, conforme postula Benveniste (2005a, p. 48), "o homem não nasce dentro da natureza mas dentro da cultura", dessa forma, "a linguagem está na natureza do homem, que não a fabricou" (2005b, p. 285), o que nos leva à constatação de que "não atingimos nunca o homem separado da linguagem e não o vemos nunca inventando-a", "é um homem falando que encontramos no mundo, um homem falando com outro homem, e a linguagem ensina a própria definição de homem" (2005b, p. 285).

Cavarero (2011), ao tematizar o primado da voz em relação à palavra, apresenta uma perspectiva que não somente pode focalizar uma forma primária e radical de relação ainda não capturada pela ordem da linguagem, mas que tem capacidade de determiná-la como relação entre unicidades. Ou seja, a filósofa italiana percebe que há algo na voz que escapa à ordem da língua, o que foi denominado "unicidade". Em uma perspectiva benvenistiana, poderíamos dizer que essa "unicidade" está ligada à subjetividade, que somente poderia ser observada, analisada, a partir de uma perspectiva que pensa a voz em relação ao discurso, a voz e a linguagem, a partir do que foi denominado por Meschonnic (2008) "semântico sem semiótico".

O ponto de vista adotado por Cavarero para refletir sobre a voz rompe com a tradição metafísica que continua interessada em insistir sobre o quê do dito e não sobre o quem do dizer. Assim, a filósofa se opõe à ideia de que não seria essencial pensar que as palavras de uma língua remetam ao homem que fala.

Tal preocupação também encontra-se na obra de Benveniste, em especial, quando este diz que "é o ato mesmo de produzir um enunciado, e não o texto do enunciado, que é nosso objeto" (2006c, p. 82). Segundo Dessons (2006), quando Benveniste fala de subjetivação se situa sobre o plano geral da linguagem, onde convém que se situe para construir uma antropologia. Dessa forma, "o plano da enunciação é o lugar legítimo, não aquele do enunciado e de seu emprego de formas linguísticas"3 (p. 170). Em Meschonnic, da mesma forma, conforme postula Dessons (apud MESHONNIC, p.137), o ritmo "é o fazer no interior do dizer, organização da enunciação, mais ainda do que do enunciado" ${ }^{4}$.

\footnotetext{
${ }^{2}$ Utilizo linguagem aqui em contraposição a língua, concebendo-a enquanto discurso, composta pelo domínio semântico e semiótico, em termos benvenistianos.

${ }^{3}$ Tradução minha; no original, lê-se: [...] le plan de l'énonciation est le lieu légitime, pas celui de l'énoncé et de son emploi des formes linguistiques.

${ }^{4}$ Tadução minha; no original, lê-se: [...] est le faire à l'intérieur du dire, organisation de l'énonciation, plus encore que de l'énoncé.
} 
Faz-se, no entanto, importante ressaltar que para Benveniste, assim como para Meschonnic, devido à concepção de linguagem que dá sustentação a seus trabalhos, o interrogar-se sobre o quem do dizer remete ao sujeito da enunciação, em Benveniste, e ao sujeito do poema, em Meschonnic, não ao homem que fala como em Levinas e Cavareiro. Para Meschonnic (1982/2009), de Saussure e Benveniste parte uma antropologia histórica da linguagem, o que significa dizer que a linguagem é constituidora dos sujeitos, da sociedade, da cultura. A linguagem é fundante, porque é arbitrária, ela cria o mundo, e não o reflete. Assim, observar o quem da enunciação é observar o sujeito da enunciação, do poema, construídos na e pela linguagem.

A discussão acerca da voz também permeou trabalhos dentro do domínio dos estudos da linguagem. Refletir acerca da proposta de Fónagy, em La vive voix, é o que farei a seguir.

\section{A VOZ E O DISCURSO EMOTIVO}

Roman Jakobson, ao prefaciar a obra La vive voix, afirma que o mérito de Fónagy estaria em contrabalancear, através de uma investigação do discurso emotivo, o estudo do discurso cognitivo e de suas transformações mitopoéticas. Dessa forma, Fónagy daria um passo decisivo em relação à investigação das sensações motoras das expressões emotivas.

Na obra La vive voix, Fónagy propõe que o princípio da condensação inerente à comunicação à viva voz supõe a distorção de uma mensagem linguística primária. Antes de ser anárquica, essa distorção se conformaria às regras estritas e relativamente simples, que seriam diferentes, contudo, daquelas que engendram os fonemas. Dessa forma, a codificação secundária consistiria em uma deformação semiótica, significativa, de uma mensagem primária. Seria, assim, uma tarefa de um modulador que não está incorporado à gramática.

A informação estética não estaria ligada, assim, a um repertório universal, ela teria um caráter pessoal, na medida em que o ponto de vista estético "não tem o caráter de intencionalidade, ele determina, na verdade, os estados interiores", "a informação estética é específica do canal que a transmite" (MOLES ${ }^{5}$ apud FÓNAGY, 1983, p. 20), não seria, pois, traduzível. No entanto, apesar de seu caráter motivado, as mensagens sonoras, gestuais não escapariam às convenções.

De acordo com Bühler (apud FÓNAGY, 1983, p. 23), "cada fonema deixa margem às realizações possíveis, e é em todas essas margens que pode se elaborar a pintura sonora"6. Assim, o estilo verbal consistiria em uma série da manipulações de sequências de sons da acentuação, da entonação, da distribuição de pausas, da ordem dos elementos significativos e transformação do sentido dos signos lexicais e gramaticais nos quais estão incluídos também os signos de pontuação.

\footnotetext{
${ }^{5}$ Abraham Moles, Théorie de l'information [1958], 1972, p. 133-135, 195 et s.

6 Tradução minha; no original, lê-se: "chaque phonème [...] laisse une certaine marge aux réalisations possibles, et c'est dans toutes ces marges que peut s'élaborer la peinture sonore."
} 
À concepção de voz apresentada por Fónagy, é preciso destacar, subjaz a concepção de língua enquanto estrutura. Trata-se de uma reflexão que propõe a lógica do descontínuo, que observa a língua sob a perspectiva de oposição entre som e sentido, postulando que este último é acrescentado, justaposto ao som ou mesmo a um sentido já estabelecido anteriormente.

Ao considerar o estudo da língua no domínio do discurso, do contínuo, cumpre romper com a oposição entre som e sentido, conforme Meschonnic (1989/2006, p. 23):

O discurso é um escândalo, porque ele rompe com a oposição entre o som e o sentido. O escândalo do sentido é a forma. É o som. Essa separação dada por natural entre o som que não tem sentido, e o sentido incarnado em um som. No entanto, a linguagem como matéria da história faz quebrar este círculo ${ }^{7}$.

A história do pensamento da linguagem propõe uma separação entre a história do som e a história do sentido. Embora tenha havido tentativas de associar tais elementos, a história de tal associação não seria mais do que a história de sua separação, como constata Meschonnic (1989/2006). Falar do som, nos estudos da linguagem, suporia uma dualidade, heterogeneidade entre o som e o sentido. Falar de sentido não seria diferente, na medida em que se trata de duas faces de uma mesma dualidade.

O que se percebe na história de tal associação é o pensar o som mais o sentido, o sentido mais o som; contudo, ao conceber o estudo da linguagem a partir do contínuo do discurso, o que se constata é que o "movimento de significar tem seu corpo, seus gestos, sua voz, sua história"8 (1989/2006, p. 57). Não se trata mais do som e do sentido, trata-se de um homem, uma mulher realmente falando, "não lhe saem mais da boca as categorias da língua, que deixam sempre um estranho resíduo, mas você é discurso e prosódia por inteiro. O infinito do dizer. O fundo do quadro também mudou. Seu retrato em linguagem o pinta como um mundo."' (1989/2006, p. 57).

A consequência de conceber a linguagem como estrutura, em Fónagy, é que se considera que existiriam níveis de acentuação, níveis de produção de sentido, como se este último pudesse ser acrescentado em camadas e como se a produção de sentidos não fosse transversal à linguagem, ao discurso. Quando se adota, no entanto, o ponto de vista do contínuo, do discurso, percebe-se que a entonação, ao mesmo tempo que é fonológica, é também aquilo que escutamos do sujeito na linguagem. É, de acordo com Meschonnic (1989/2006), sua presença, seu modo de intervenção, que porta, engloba, transborda, e também pode contradizer o sentido das palavras. Não se trataria, portanto, somente da emoção, aí entraria a relação do sujeito com sua psique, sua história. A voz seria, assim, mais que uma simples portadora de palavras, que um órgão de fala.

\footnotetext{
7 "Le discours est un scandale, parce qu'il ronge l'opposition entre le son et le sens. Le scandale du sens, c'est la forme. C'est le son. Cette séparation donné pour une nature, entre le son qui n'a pas de sens, et le sens incarné dans un son. Pourtant, le langage comme matière de l'histoire fait craquer ce cercle."

${ }^{8}$ Tradução minha; no original, lê-se: "[...] mouvement de signifier a votre corps, vos gestes, votre voix, votre histoire."

9 Tradução minha; no original, lê-se: "Il ne vous sort plus de la bouche les catégories de la langue, qui laissent toujours un drôle de résidu, mais tout entier vous êtes discours et prosodie. L'infini du dire. Le fond du tableau aussi a changé. Votre portrait en langage vous peint comme un monde."
} 
Ao discutir a voz na produção artística, Fónagy (1983) afirma que a entonação obedeceria a leis assimiláveis àquelas que regem as formas musicais. Essa interpretação ultrapassaria, portanto, a sua função inicial de transmitir, de modo inteligível a todos, as experiências e, antes de tudo, os sentimentos. Para o teórico, ao distanciar-se da fala de todos os dias e reaproximar-se da música, tal entonação, longe de empobrecer, enriquecer a mensagem, acrescentaria meios de expressão musical às possibilidades de expressão linguística.

Assim, a voz evocaria uma linguagem pré-linguística e translinguística. A musicalidade seria independente da regularidade das vibrações, da musicalidade no sentido técnico do termo, o que significa que os versos de um poema, por exemplo, seriam musicais em um sentido mais largo e mais profundo, em que até mesmo o sussurro ou a ausência de musicalidade física se tornariam expressões "musicais" não verbais de conteúdos pré-conceituais que escapam à língua e que se exprimem em geral com a ajuda da música vocal e instrumental.

Essa reflexão de Fónagy carece, no entanto, de atentar para aquilo que discute Benveniste, no texto "Semiologia da língua", em Problemas de lingüística geral II, quando, ao buscar compreender o funcionamento do sistema da língua, o faz a partir da relação, da comparação com outros sistemas semióticos, e percebe que as unidades de cada sistema são diferentes, justamente e porque as leis que as regem são leis que emanam do sistema. Dessa forma, as leis que regem as formas musicais desconhecem inevitavelmente a especificidade da linguagem, que não vem e não pode vir da música. Conforme nos lembra Meschonnic (1982/2009, p.126), a aproximação e a associação da música com a poesia "dessemantiza o discurso, retira a linguagem dela mesma"10.

Ainda observando o que se pensou acerca da voz dentro do domínio dos estudos da linguagem, abordo na seção seguinte a discussão proposta por Parret (2002).

\section{A ESTÉTICA DA VOZ}

Em La voix et son temps, Herman Parret observa que a voz, considerada uma "matéria" sem estrutura, já que representa a pura variabilidade, foi desconsiderada pelos estudos da linguística estrutural. Segundo o teórico, o termo voz não aparece uma só vez nos Princípios de fonologia de Troubetzkoy, obra considerada a bíblia da fonologia estrutural. Os grandes estruturalistas como Jakobson, Hjelmslev, Troubetzkoy, seriam solidários quanto a esse colocar entre parênteses a voz, e não hesitariam em tomar Saussure para sustentar seu ponto de vista.

Conforme Parret (2002), para o Saussure "oficial", a voz, enquanto substância positiva, substrato sólido da fala, não se transformaria em signo linguístico. Ademais, a eliminação da voz seria mesmo a condição de possibilidade para que a nova ciência, a semiologia estrutural, pudesse ser introduzida. $O$ vocal seria o lugar da alteridade radical; e o "triunfo do binarismo", para utilizar a expressão de Parret, em Principes de phonologie (1939) de Troubetzkoy e em Fundamentals of Language (1956) de Roman Jakobson aniquilaria a voz.

\footnotetext{
${ }^{10}$ Tradução minha; no original, lê-se: "Desémantise le discours, retire le langage à lui-même."
} 
É no Saussure "noturno" que Parret (2002) se ancora para pensar uma esfera qualitativa da voz. Segundo o autor, há nos Manuscritos de Harvard uma discussão acerca da esfera qualitativa sobre a qual ganham forma as semelhanças, identidades e diferenças, como as saliências. Essa esfera seria física; o físico seria a esfera, o ambiente, o horizonte acústico. A fonética semiológica seria uma psicoacústica. Saussure pareceria ainda sugerir que haveria um alcance qualitativo da sonoridade pelo ouvido, em que o ambiente físico seria copercebido como o contexto de "l'analysandum" (semelhanças, identidades, diferenças). Dessa forma, tomar um som como um valor seria contextualizar o "analysandum" acústico.

Parret (2002) resgata, ainda, a discussão feita por Aristóteles sobre a voz, em que o filósofo postula que a voz enraíza o homem na animalidade ao mesmo tempo que constitui uma ruptura radical com o mundo animal, pois o homem e o animal teriam em comum o poder de exprimir a dor e o prazer pelo som de sua voz, no entanto, somente o homem poderia enunciar o que é útil e nocivo e, consequentemente, o que é justo e o que é injusto.

Para Aristóteles, à voz se imporia uma restrição semântico-cognitiva, ou seja, a voz porta, além de suas qualidades intrínsecas, representações semânticas que não são ainda necessariamente significados de palavras ou outras sequências discursivas. Ela evocaria, também, uma certa beleza, onde a concordância entre a voz e o ouvido seria eufônica, sinfônica.

Partindo de tal reflexão, Parret (2002) postula que a significância residiria antes no que há de musical na voz, em sua tonalidade, em sua cor e em seu timbre, no seu espasmo rítmico. A voz seria uma parte do corpo que transcorre, uma parte do corpo se separando, o corpo em evanescência.

Assim, partindo dessa relação entre o corpo e a voz, o autor discute sobre o que chamou de "a voz antes da linguagem", o balbucio, o grito, o soluço, o gemido; "a vozfala" e a "voz depois da linguagem", o canto, essencialmente.

Interessa à abordagem fenomenológica da qualidade vocal, de acordo com Parret (2002), a terminologia impressionista, ou seja, as etiquetas impressionistas da voz, na linguagem cotidiana, que se referem a três traços: aos traços segmentais, aos traços que se referem ao dinamismo vocal e aos traços que se referem mais especificamente ao processo fisiológico da produção vocal.

A qualidade vocal, nessa ótica, seria o produto tonal complexo resultante de uma série de fatores heterogêneos que vão da anatomia a mais objetiva até a estética mais intuitiva. Assim, para que haja qualidade, é necessário levar em conta determinantes psicológicos, que dizem respeito à personalidade, à emotividade, ao temperamento, ao gosto e mesmo a uma certa evolução estética largamente influenciada pela norma cultural.

A qualidade da voz ou seu timbre vocal consiste, segundo o autor, em traços suprassegmentais e paralinguísticos. Nesse sentido, reconhecer um timbre significa projetar uma fonte por trás de uma voz, o corpo animado de uma pessoa, de forma a se confundir o estilo da voz e o da pessoa que a fez ressoar. Ademais, compreender a qualidade da voz significa abandonar-se à sedução.

O timbre da voz, na esteira de Parret (2002), seria um fenômeno quantitativo holístico, na medida em que o timbre se desenrola em uma duração, em um tempo que 
não pode ser segmentado. Esse entrelaçamento da voz e do tempo configurar-se-ia como obstáculo à análise de componentes e quantitativa, por isso, afirma o autor que "o timbre da voz é antes o território dos poetas e dos apaixonados do que dos foneticistas"11 (p. 51).

Parret (2002) denuncia a negligência do trabalho com a voz no domínio da fonologia, principalmente nas pesquisas de Troubetzkoy e Jakobson, e procura pontuar que embora o Saussure "oficial" também tenha negligenciado tal questão, os Manuscritos de Harvard mostram outra realidade. Parret (2002) vai além em seu questionamento e afirma que a fonologia estrutural precisou excluir o estudo da voz pelo fato de que tal objeto não caberia no binarismo proposto por tal campo de estudos. Assim, o autor reivindica o estudo do tema da "voz" para o campo da linguística e comprova que essa reflexão já está presente nos manuscritos do linguista genebrino.

É preciso pontuar, no entanto, que embora Parret denuncie o tratamento da voz pelos estruturalistas, ao buscar discutir essa temática não altera seu ponto de vista sobre a linguagem e mantém-se em um paradigma que concebe a língua enquanto sistema e/ou estrutura. Deriva de tal concepção de linguagem a possibilidade de o autor distinguir entre "la voix d'avant le langage", "la voix-parole" e "la voix d'après le langage". Ao observar a linguagem a partir do ponto de vista do discurso, do uso, nos vemos diante da impossibilidade de distinguir claramente os domínios que separam essas três esferas apresentadas.

O autor recorre ainda à tripartição porposta por Peirce para a análise da voz, ao afirmar que o som é um signo, que pode significar segundo um ícone, um índice ou um símbolo. Esse eixo semântico funcionaria como polaridade, a naturalidade versus a convencionalidade. Assim, o grito e o balbucio, da "voz de antes da linguagem", se situariam ao lado do "natural", o que foi denominado "pré-semiotização", já que a naturalidade da relação som-sentido se impõe de tal forma que nenhum interpretante a mediatiza. Segundo essa lógica, o som imitativo, a onomatopeia, configurar-se-ia como plenamente semiotizada e a semelhança transformaria o som em ícone. A indexicalização seria um segundo tipo de semiotização, como é o caso das semiotizações sinestésicas, em que o som funciona como um índice de um fenômeno não acústico "emprestado" a um outro domínio sensorial que não o auditivo.

Propõe ainda Parret (2002) que se redefina o que chamou de "dé-naturalisation" ou estetização do som vocal através da prática de uma fenomenologia tão sutil quanto aquela de Roland Barthes, que distingue três tipos de escuta: na primeira, a audição vai em direção aos índices; na segunda, haveria um deciframento, em que se tentaria captar o que seriam não mais os índices, mas os signos; e enfim na terceira, não se buscaria mais os signos determinados, no nível do que é dito, mas antes quem fala em um espaço intersubjetivo ou um jogo de transferência, em que haveria a escuta de uma significância.

A possibilidade de haver tonalidade estaria indissociavelmente ligada à temporalidade. Compreender a tonalidade da voz seria compreender a temporalidade da relação da voz com o ouvido. Reconhecer uma voz seria reconhecer o tom dessa voz. Esse reconhecimento estaria ancorado em uma experiência de tempo que marca o intercorpo enquanto relação de dois sujeitos. O sensível e o social vão, portanto, se interdefinir: a sensibilização do social provoca e pressupõe a socialização do sensível.

\footnotetext{
${ }^{11}$ Tradução minha; no original, lê-se: "[...] le timbre de la voix, c'est le territoire des poètes et des amoureux plutôt que des phonéticiens".
} 
O significante corporal e sonoro "conotariam" a subjetividade profunda dos interlocutores, que figuraria como o motor da comunicação discursiva. A conversação se relaciona ao estado do mundo (semântica), ela "representa" quase objetivamente a norma social ou os papéis actanciais (pragmática) e enfim "apresenta" a materialidade do significante (corpo, voz) e acrescenta, assim, este fator incontornável da seduçao (estética) (PARRET, 2002).

Assim, a sedução estética, que se acrescenta à informação semântica e à intensificação pragmática, se torna o fundamento da comunicação, na medida em que seria a sedução que fundaria a possibilidade mesma do estar junto na comunicação interpessoal. A possibilidade de os sujeitos estarem juntos se realiza no nível do "significante" de seus corpos, seus olhares, suas vozes.

Ao compreender o tom da voz, ou a qualidade da voz, Parret (2002) busca pensar as características que formam a identidade de uma voz, que permitem reconhecer a unicidade da voz. Consequentemente, devido à sua invisibilidade e outros meios corporais, a voz possibilitaria uma relação com a subjetividade do outro, ou seja, a voz do outro permite alcançar a interioridade de uma alma guardada que se deixa desvendar essencialmente na escuta.

Essa voz, plenamente corporal, portaria um buquê de temporalidades. Escutar-seiam várias "vozes" superpostas na voz, e cada uma dessas vozes que se combinam portaria seu próprio tempo. Três "vozes" comporiam polifonicamente a voz, a "voz enunciante", a "voz narrativa" e a "voz actancial ou pathémisée". A primeira delas está no evento da voz-fala, do ato vocal do discurso; essa voz "transpõe" linearmente as categorias e técnicas gramaticais e retóricas que estão à disposição do temporalizador em ação. A essa voz enunciante acrescentar-se-iam as manifestações de natureza actancial e narratológica; a voz de um actante manifestaria a consistência aspectual, no entanto, a voz actancial não coincidiria necessariamente com a temporalidade da voz enunciante. Por fim, o sujeito temporalizador seria também um sujeito modal, um sujeito que possui a voz modalizada; o sujeito se "temporaliza" a partir de sua qualidade modal, seu tempo se projeta como uma dinâmica que possui a especificidade de um conteúdo modal.

Nos estudos literários, temos a discussão da temática da voz a partir do trabalho de Zumthor. Essa discussão será proposta na seção seguinte.

\section{UMA POÉTICA DA VOZ}

Em Introdução à poesia oral, Zumthor (1997) privilegia uma reflexão sobre a voz ligada à poesia oral. $\mathrm{O}$ autor apresenta discussões bastante pertinentes não apenas para pensar questões que envolvem os estudos literários, mas também os estudos da linguagem.

Zumthor (1997) não considera a oralidade de modo negativo, o que acontece quando ela é concebida a partir dos traços que contrastam com a escrita. A oralidade, dessa forma, não significa analfabetismo, pois não são intrínsecos a este os valores próprios da voz e de qualquer função social positiva que a esta possa ser atribuída. Ademais, o teórico contesta que possa haver uma sociedade de pura oralidade. 
A diferença entre as produções orais e escritas estaria em que as primeiras interiorizariam a memória do mesmo modo que a espacializariam, já que a voz se estende num espaço, cujas dimensões se medem pelo seu alcance acústico, aumentada ou não por meios acústicos, que ela pode ultrapassar. Por outro lado, a escrita também é evidentemente espacial, mas o é de outra maneira; seu espaço é a superfície do texto. A repetitividade indefinida da mensagem em sua identidade intangível lhe dá garantias de vencer o tempo.

Para Zumthor (1997), o simbolismo primordial integrado ao exercício fônico se manifestaria eminentemente no emprego da linguagem, e aí se enraizaria toda a poesia. No entanto, uma voz sem linguagem, como o grito, não seria bastante diferenciada para transpor a complexidade das forças do desejo que a animariam. Da mesma forma, essa impotência afetaria também a linguagem sem voz que seria a escrita.

A voz, assim concebida, seria indizibilidade apta a se revestir de linguagem. Ela teria qualidades materiais como o tom, o timbre, o alcance, a altura, o registro, e a cada um deles se ligaria um valor simbólico. A consequência disso é que a linguagem seria impensável sem a voz. Por outro lado, a voz ultrapassaria a palavra. Seria aquilo que designa o sujeito a partir da linguagem, ou seja, a voz não traria a linguagem, esta nela transitaria sem deixar traço. Para o autor, a voz se diz quando diz, seu uso ofereceria um prazer, alegria de emanação que, sem cessar, a voz aspiraria a reatualizar no fluxo linguístico que ela manifesta e que, por sua vez, a parasita.

A phoné não se uniria imediatamente ao sentido, mas lhe prepararia o meio em que ele se afirmaria. Assim, toda a oralidade significaria vocalidade, e o logocentrismo, proposto por Platão, se desfaria. Haveria, então, um duplo desejo na fala, o de dizer e o que envolve o teor das palavras ditas. A intenção do locutor não seria mais apenas de comunicar uma informação, mas de provocar também o reconhecimento dessa intenção, ao submeter o interlocutor à força ilocutória de sua voz.

A tensão entre a palavra e a voz procederia a uma contradição insolúvel no seio de sua inevitável colaboração, entre a finitude das normas do discurso e a infinidade da memória; isto é, entre a abstração da linguagem e a espacialidade do corpo. Assim, o texto oral nunca preencheria inteiramente seu espaço semântico.

Uma poética da oralidade, segundo Zumthor, deveria, então, interrogar-se sobre as relações instáveis das quais resulta, em nível das concatenações de elementos e de seus efeitos de sentido, a economia particular do texto dito: sua intensindade, sua tendência a reduzir a expressão ao essencial, sua ausência e artifícios refreando as reações afetivas; a predominância da palavra em ato sobre a descrição; os jogos de eco e de repetição; o imediatismo das narrações, cujas formas complexas se constituem por acumulação; a impessoalidade, a intemporalidade.

Para Zumthor (1997), a poesia aspiraria a um propósito ideal, a se depurar das limitações semânticas, a sair da linguagem, ao alcance da plenitude, em que tudo o que não for simples presença será abolido. A escrita reprimiria ou esconderia tal aspiração, enquanto a poesia oral acolheria seus fantasmas e tentaria lhes dar forma, através de frases absurdas, repetições acumuladas até o esgotamento de sentido, sequências fônicas não lexicais, puro vocalizes. 
Zumthor (1997) assume que a prosódia de um poema oral refere-se à pré-história do texto dito ou cantado, à sua gênese pré-articulatória, cujo eco é pela prosódia interiorizado. Fundamentalmente, a poesia oral só teria "regras" prosódicas; tal poesia não teria a função de transmitir conteúdos inteligíveis, mas apenas sons e ritmos. Para o autor (1997, p.173), "o ritmo é sentido, intraduzível em língua por outros meios".

Zumthor (1997) não distingue sujeito enunciador e sujeito da enunciação, o sujeito empírico do sujeito da linguagem, por exemplo; o que o leva a propor que, na forma da poética oral, a performance pode ser considerada um elemento e principal fator constitutivo. Considerada como instância de realização plena, ela determinaria todos os outros elementos formais que seriam "pouco mais que virtualidades" (1997, p. 55). A performance seria somente compreensível e analisável do ponto de vista de uma fenomenologia da percepção.

Considerando tal postura, Zumthor (1997) afirma que, na performance ritual, a conotação seria tão poderosa que poderia constituir por si só a significação do poema, embora admita que na performance de "tempo livre" o efeito tende a se diluir, mesmo que não se apague inteiramente. Essas modalidades espaciais da performance interfeririam nas do tempo, pois o lugar tanto quanto o momento poderiam ser aleatórios, impostos por circunstâncias estranhas à intenção poética. Contudo, o autor insiste na percepção de que o condicionamento espacial seria mais forte e mais constante do que o temporal.

Essa impossibilidade de transgressão dos esquemas discursivos comuns, ao introduzir o germe do anti-discurso, através de uma maneira específica marcada, que se dá de forma diferente em cada lugar, desmantelaria a ideia de um "fechamento do texto". Essa constatação leva Zumthor a afirmar que o discurso do poema não poderia ter em si mesmo seu próprio fim. O que restaria ao poema de força referencial, nesse caso, diria respeito à focalização, no contato entre os sujeitos corporalmente presentes na performance, ou seja, o portador da voz e quem a recebe.

O ouvinte faria parte da performance, ocupando um papel tão importante quanto o intérprete. A poesia seria então aquilo que é recebido, no entanto, tal recepção seria um ato único, fugaz, irreversível e individual, já que o estudioso duvida de que se possa viver a mesma performance de maneira idêntica.

Apresentadas algumas visões que direcionam a construção de diferentes conceitos de voz e, consequentemente, diferentes estudos sobre a voz, passo em seguida à apresentação de uma proposta, que se ancora no projeto de uma antropologia histórica da linguagem, proposto por Meschonnic (1982/2009).

\section{POR UMA ANTROPOLOGIA HISTÓRICA DA VOZ}

Na introdução deste artigo, utilizando-me das palavras de Meschonnic (1989/2006), atentei para a ideia de que a visão que temos de linguagem constitui-se como o nosso retrato. Durante a apresentação das diferentes seções, busquei estabelecer um debate elucidativo das consequências de se assumir uma determinada visão de linguagem, no sentido de observar como se constroem, a partir dela, as noções de sujeito, subjetividade, intersubjetividade, as relações entre a linguagem e os sujeitos, a linguagem e a realidade, a linguagem e a cultura, bem como a forma como se concebe a construção dos sentidos. 
De acordo com essse debate, é possível observar que, em geral, as discussões envolvendo a voz o fazem a partir de sua relação com a língua. O que deve ser destacado, no entanto, é que a noção de língua de que essas posições teóricas lançam mão é aquela que a concebe enquanto estrutura e/ou enquanto sistema. Ou seja, predomina o pensamento do privilégio às unidades da língua, ao descontínuo, para utilizar os termos de Meschonnic.

Se a voz é o lugar da individualidade, da unicidade, da subjetividade, proponho aqui que se deixe o paradigma do descontínuo, para pensar a linguagem a partir do paradigma do contínuo, isto é, a partir do discurso. Como nos lembra Benveniste, conforme destacado na seção 3, um pensamento da individuação, do singular, do particular só pode recusar o signo, que existiria em si, fundaria a realidade da língua, mas não encontraria aplicações particulares, enquanto a frase, o discurso, não seria senão particular.

É, contudo, da mesma forma, imperativo que se atente para o fato de que essa alteração do ponto de vista sobre a linguagem não significa negar a presença de unidades na língua, mas considerá-las a partir de sua imbricação mútua com o discurso. O que se altera é a percepção de que as unidades combinadas constituem o discurso, e passa-se a considerar que é o discurso como um todo que atribui os valores a cada unidade.

Essa alteração do ponto de vista acerca da linguagem nos coloca diante da impossibilidade de separar a linguagem da voz e a voz da linguagem, na medida em que as fronteiras que separam o que Parret (2002) chama de "voz antes da linguagem" e "voz após a linguagem" se tornariam bastante fluidas. Dessa forma, conforme defende Meschonnic (2009), a voz e o discurso, o discurso e a voz são concebidos como indissociáveis, necessários um ao outro, assim como o significante e o significado, no signo.

Pensar, assim, uma antropologia histórica da voz significa pensar a voz como uma problemática que não pode estar alheia à problemática da linguagem e da subjetividade. O termo antropologia, no sintagma apresentado, nasce de uma leitura da obra benvenistiana por Meschonnic (1982/2009), e estabelece que a voz é o lugar da constituição do sujeito, de subjetividades, ou mais propriamente, de intersubjetividades, na medida em que, como ensina Benvensite (2006b), ao se enunciar, o "eu" estabelece uma outra pessoa, ao qual esse "eu" diz "tu" e que diz "tu" ao "eu". Tais termos não podem ser concebidos um sem o outro, são, portanto, complementares.

Ao considerar a voz como antropológica, pode-se afirmar que os sujeitos se constroem na e pela voz, e a voz no e pelos sujeitos, na empiricidade do discurso. Percebese, dessa forma, através da voz, a constituição da subjetividade, da intersubjetividade e da transubjetividade. Essa subjetividade é resultado da transformação do que se considera sentido ou valor na língua em valores no discurso e somente no discurso, em quaisquer níveis linguísticos.

O termo histórica intervém para descatar que esse sujeito que nasce na e pela voz, na empiricidade do discurso, ao dizer e dizer-se, também historiciza-se, constrói a sua história, inventa uma nova historicidade no discurso.

A partir dessa concepção de linguagem e de voz, percebemos que a voz não pode mais ser concebida necessariamente enquanto som. Para Meschonnic (2009), o considerar 
a voz necessariamente como som nasce de uma confusão entre subjetividade e individualidade, subjetivismo e individualismo. Para o autor (1989/2006), a confusão entre a voz e o fônico é solidária da mesma confusão que identifica o ritmo enquanto fônico.

Pensando a voz e a subjetividade como elementos que se constituem mutuamente, que fazem parte da mesma problemática, podemos afirmar que, ao nos debruçarmos sobre os discursos, não é mais o som que escutamos, mas o sujeito. Assim, é necessário que o analista se coloque numa atividade de escuta da enunciação, tanto quando se depara com textos falados, quanto com textos escritos.

Ademais, é necessário observar que não se pode separar a forma do sentido, o som do sentido. É em uma relação de imbricação mútua entre esses elementos que se constrói a significância no discurso. Benveniste, ao se referir a tais elementos, utiliza a expressão "noções gêmeas de sentido e forma" (2006b, p.221). Para o linguista, tentar reinterpretar a oposição entre tais termos no funcionamento da língua integrando-a e esclarecendo-a, significa perceber que essa oposição contém, em sua antítese, o ser mesmo da linguagem, pois de um só golpe nos coloca no centro do "problema mais importante, o problema da significação" (2006b, p. 222).

Ao analisar os poemas de Baudelaire, Benveniste (2011) postula que a dicotomia entre forma e sentido tem menos sentido ainda no texto literário do que em qualquer outro lugar, pois o sentido em poesia estaria no interior da própria forma.

Para Meschonnic (1989/2006, p.59), no discurso há uma ritmicidade e uma prosódia que são denominadas "signifiance", isto é, uma organização, uma difusão de efeitos que se constituem, que se constroem indefinidamente. A significância, para o autor, não diz respeito aos sentidos lexicais das palavras, da sua significação em uma determinada situação com um determinado emissor e destinatário, mas ela os carrega, os atravessa, os une e os desune; enfim, os engloba.

Outra consequência da mudança de ponto de vista sobre a linguagem está na discussão sobre o sentido. Em Fónagy (1983), haveria uma mensagem primária que seria transformada por um modulador, e o estilo verbal seria uma mensagem secundária engendrada com a ajuda de um sistema de comunicação pré-verbal e integrado à mensagem linguística; Zumthor (1997) postula que a phôné não se uniria imediatamente ao sentido e que haveria um duplo desejo na fala, o de comunicar uma informação e o de submeter o interlocutor à força ilocutória. Percebe-se, portanto, que o sentido é concebido em camadas, como se pudesse ser acrescentado a outro sentido já existente.

A partir da concepção de linguagem aqui adotada, proponho a construção de sentidos no âmbito do discurso, onde essa construção será sempre nova, particular e singular. Segundo esse ponto de vista, é impossível determinar o que é exclusivamente do âmbito da linguagem e aquilo que é do domínio exclusivamente da voz. No contínuo do discurso, é a relação de imbricação entre ambos que contrói a signficância do texto.

Não há, de acordo com esse ponto de vista, níveis de acentuação, níveis de produção de sentido, ao contrário, este é percebido enquanto transversal à linguagem, ao discurso. Dessa forma, ao mesmo tempo que a entonação é fonológica, é também aquilo que escutamos do sujeito em sua linguagem. 
A análise da voz em discursos, devido a seu caráter transversal na produção de sentidos, passa por todos os níveis de linguagem: acentual, prosódico, sintático, morfológico. Observar a voz e como esta constrói sentidos, nessa perspectiva, nos leva a observar o ritmo, as rimas, os ecos prosódicos, os silêncios do discurso, o que tem como consequência compreender que a produção de sentidos nos textos e nas obras não se organiza apenas nas relações sintagmáticas, mas também através das relações associativas produzidas pelos discursos.

\section{PALAVRAS FINAIS}

Conforme o título do artigo, propus aqui fazer um "Ensaio sobre a voz", no sentido de refletir e discutir acerca de trabalhos que tematizam a voz, pensando acerca das concepções que estão imbricadas em cada uma das noções que são apresentadas, em especial, no que tange à observação daquilo que se constrói a partir de uma determinada visão de linguagem.

Ao buscar pensar o contínuo do discurso e, consequentemente, alterar o ponto de vista de que se observa a linguagem, propus uma concepção de voz que foi aqui denominada "uma antropologia histórica da voz", que faz eco à proposta de uma "antropologia histórica da linguagem", apresentada por Meschonnic (1982/2009). Considerando essa concepção de linguagem, propus alguns questionamentos e reflexões que devem fazer parte das considerações da noção de voz aqui apresentada. Tais considerações, conforme destaquei na introdução, apresentam-se como basilares para uma discussão teórica acerca da temática apresentada.

\section{REFERÊNCIAS}

BENVENISTE, É. Saussure após meio século. In: Problemas de lingüística geral I. Campinas:

Pontes Editora, 2005a.

Editora, 2005b.

Da subjetividade na linguagem. In:

Problemas de lingüística geral I. Campinas: Pontes 2006a.

Semiologia da língua. In: Problemas de lingüística geral II. Campinas: Pontes Editora,

A forma e o sentido na linguagem. In: Problemas de lingüística geral II. Campinas: Pontes Editora, 2006b.

O aparelho formal da enunciação. In: Problemas de lingüística geral II. Campinas: Pontes Editora, 2006c.

Baudelaire. France: Limoges, Éditions Lambert-Lucas, 2011.

CAVARERO, A. Vozes plurais: filosofia da expressão vocal. Belo Horizonte: Editora UFMG, 2011.

DERRIDA, J. A voz e o fenômeno: introdução ao problema do signo na fenomenologia de Husserl. Tradução de Lucy Magalhães. Rio de Janeiro: Jorge Zahar Ed., 1994.

DESSONS, G. Émile Benveniste, l'invention du discours. Paris: Press, 2006.

FÓNAGY, I. La vive voix. Paris: Payot, 1983.

MESCHONNIC, H. La rime et la vie. France: Éditions Verdier, 1989/ Gallimard, 2006.

Benveniste: sémantique sans sémiotique. In: Dans le bois de la langue. Paris: Édition

Laurence Teper, 2008. 

1982/2009.

Critique du rythme: anthropologie historique du langage. Lonrai, France: Éditions Verdier,

PARRET, H. La voix et son temps. Bruxelles: Éditions De Boeck Université, 2002.

TRABANT, J. Le Humboldt de Henri Meschonnic. In: DESSONS, G.; MARTIN, S.; MICHON, P. Henri Meschonnic, la pensée et le poème. Paris: Éditions IN PRESS, 2005.

ZUMTHOR, P. Introdução à poesia oral. São Paulo: Editora HUCITEC, 1997.

Recebido em: 04/07/17. Aprovado em: 04/01/18.

Title: Essay about voice

Author: Daiane Neumann

Abstract: This paper discusses the voice, a subject that is not common and therefore not considered in the language field. Thereunto, this work reflects on the construction of this object in distinct theoretical perspectives, from distinct fields. The goal of reflecting on different conceptions of voice is to elucidate the notion of language in each of them. Finally, considering a change of viewpoint about language, a proposal of historical anthropology of voice is presented, based on the project of an historical anthropology of language, proposed by Meschonnic (2009).

Keywords: Voice. Language. Historical anthropology of voice.

Título: Ensayo sobre la voz

Autora: Daiane Neumann

Resumen: El presente artículo trata de una temática poco considerada y discutida en los estudios del lenguaje, es decir, la voz. Para ello, utiliza reflexiones propuestas acerca de la construcción del objeto voz en diferentes perspectivas teóricas y en diferentes campos del conocimiento. El objetivo de hacer el pasaje por diferentes concepciones de voz es buscar elucidar la concepción de lenguaje que subyace a cada una de ellas. Al fin, a través del cambio del punto de vista acerca del lenguaje, es presentada la propuesta de una antropología histórica de la voz, anclada en el proyecto de una antropología histórica del lenguaje, presentado en Meschonnic (1982/2009).

Palabras-clave: Voz. Lenguaje. Antropología histórica de la voz.

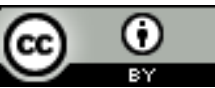

Este texto está licenciado com uma Licença Creative Commons Atribuição 4.0 Internacional. 